\title{
Reseñas
}

\section{Ginnobili, Santiago (2018). La teoría de la selección natural. Una exploración metacientífica. Bernal: Universidad Nacional de Quilmes, 256 págs.}

La teoría de la selección natural ha significado un cambio paradigmático en cuanto al modo de comprender qué somos y cuál es nuestra relación con la naturaleza. "El origen de las especies" no solo es una obra original y cautivante, sino que está escrita en un lenguaje accesible al público general, lo cual sin embargo ha sido la causa de numerosos desacuerdos a la hora de interpretar con precisión sus principales postulados. Por ello, en "La teoría de la selección natural. Una exploración metacientífica", Ginnobili se propone realizar un trabajo de reconstrucción que permita arrojar luz sobre la estructura de la teoría darwiniana, mostrando su relevancia en la biología evolutiva actual y defendiendo su carácter científico genuino.

El objetivo del libro, pues, no se limita a una mera explicación de la teoría en un sentido biológico, sino que pretende ser "una exploración metacientífica": esto es, un examen exhaustivo de los aspectos metodológicos y conceptuales que revelan la estructura de una teoría científica auténtica y consistente tras las descripciones que Darwin realiza a lo largo de su obra, especialmente en "El origen de las especies". Para ello, Ginnobili se vale metodológicamente de las herramientas de análisis del estructuralismo metateórico. El estructuralismo metateórico es un programa de investigación fundado por Sneed en la década de los ' 70 , al cual se unieron posteriormente los aportes de otros investigadores como Stegmüller, Balzer y Moulines, que presenta una metodología de análisis de teorías científicas. Partiendo de la tradición empirista lógica del rechazo a la especulación metafísica y el uso de instrumentos lógico-matemáticos para el análisis de teorías y la elucidación de sus conceptos, el estructura-

* Unidad de Ciencia y Desarrollo, Facultad de Ciencias, Udelar (Uruguay). E-Mail: camilalopez@fcien.edu.uy 
lismo metateórico aporta un marco conceptual más complejo con nuevas herramientas que permiten clarificar la estructura esencial de las teorías. El punto de partida de esta línea de investigación es la consideración de las teorías no como meros conjuntos de enunciados sino como conjuntos de estructuras complejas. Justamente, este conjunto de estructuras subyacentes a las afirmaciones darwinianas es el que Ginnobili se propone revelar y clarificar en este libro; y es en el uso de esta metodología que radica la novedad y originalidad de su propuesta.

Una de las tareas que realiza el estructuralismo metateórico consiste en distinguir los conceptos que son específicos de la teoría y la presuponen (T-teóricos) de aquellos que son independientes de la teoría, proveniendo en cambio de otras teorías, externas o subyacentes (T-no teóricos). En este sentido, el autor realiza un examen de los principales conceptos empleados en la teoría darwiniana, con el fin de definirlos con precisión y establecer el carácter de su relación con la teoría. El principal concepto analizado es el de "adecuación", que el autor prefiere utilizar en lugar de "adaptación" para evitar ambigüedades. Se entiende que un organismo tiene "adecuación" cuando "tiene un rasgo que realiza cierta función de manera altamente efectiva en cierto ambiente" (Ginnobili 20I8, p. 25). El concepto de adecuación es clave para la teoría de la selección natural, que en definitiva consiste en un mecanismo para explicar la adecuación de los organismos a su entorno. Sin embargo, ¿es el concepto de "adecuación" inherente a la teoría de la selección natural? Ginnobili encuentra que no: es un concepto previo a la teoría. Desde un enfoque original, sostiene que el concepto de "adecuación" presupone otra teoría subyacente, que denomina "teoría funcional biológica". Esta teoría tiene todas las características de una teoría científica (tiene una ley fundamental, leyes específicas, y un conjunto de nuevos conceptos que dan cuenta de ellas) y puede ser formulada informalmente del siguiente modo: "para todo organismo, si el organismo tiene cierto objetivo, ciertos efectos de alguno de sus rasgos en ciertas condiciones satisfacen tal objetivo" (Ginnobili, 20I8, p.47). El autor argumenta que el lenguaje funcional que utiliza Darwin en su obra, en el marco del cual se utiliza el concepto de "adecuación" (los rasgos "adecuados" son los rasgos que "cumplen una función") es propio de la "teoría funcional biológica" (respecto a esa teoría, sí es un T-teórico). Como consecuencia, este tipo de conceptos no se derivan de la observación, sino de la aplicación de una teoría científica específica. Aquí comienza a vislumbrarse la riqueza de la reconstrucción desde un análisis basado en el estructuralismo metateórico: la adscripción de un concepto fundamental a una teoría científica subyacente equipara las expli- 
caciones funcionales darwinianas a otras explicaciones de otras ciencias. Ginnobili se esfuerza por mostrar que las explicaciones funcionales son aplicaciones de una teoría científica. Si no se definen, es porque, como en toda teoría, son parte de un conjunto de conceptos específicos de una teoría científica no definibles por fuera de ella.

Habiendo establecido la naturaleza de una de las teorías científicas subyacentes, el autor se dedica a reconstruir la propia teoría de la selección natural. Con el fin de resolver malentendidos y ambigüedades que encuentra en diferentes reconstrucciones de la teoría tras una revisión crítica, establece una distinción entre la "teoría de la selección natural histórica" y la "teoría de la selección natural no histórica". La primera sería una explicación descriptiva que apela a leyes presentes en la segunda, por tanto, es en esta segunda que decide concentrarse para desarrollar su análisis. La "teoría de la selección natural no histórica" tiene una ley fundamental que el autor reconstruye a partir de una serie de casos, y presenta con el siguiente enunciado general: "Los organismos más adecuados tienden a mejorar su aptitud, o la aptitud de la comunidad a la que pertenecen, tendiendo a mejorar, de ser los rasgos en cuestión heredables, en consecuencia, su éxito reproductivo diferencial o el éxito reproductivo diferencial de la comunidad a la que pertenecen" (Ginnobili, 20I8, p. 92). Posteriormente, se desarrolla un examen en detalle de los conceptos asociados a esta ley, se expone su formulación formal y se compara con otras reconstrucciones de la teoría. El análisis permite a Ginnobili abordar a continuación algunas discusiones clásicas en torno a la teoría de la selección natural.

Un debate recurrente se asienta en la acusación de irrefutabilidad del "principio de supervivencia del más apto". Ginnobili pretende desarticular esta acusación, no probando la refutabilidad de tal principio, sino criticando la propia exigencia de refutabilidad para determinar el carácter científico de una ley. A partir de una comparación con otras leyes fundamentales cuya cientificidad sí es comúnmente aceptada, como la ley fundamental de la mecánica clásica, encuentra que las leyes fundamentales suelen ser de carácter abstracto e incluso analítico, pero eso no implica que no sean científicas o que no sean teorías universales en un sentido interesante. De descartar toda ley irrefutable, habría que declarar acientíficas muchas de las leyes de teorías actualmente aceptadas. La ley fundamental de la teoría de la selección natural puede eventualmente ser entendida como analítica e irrefutable en un sentido general, pero no por eso es vacua. E incluso, en un sentido específico, de ella se deducen aplicaciones particulares que sí son refutables. 
Posteriormente, se discute si la teoría de la selección natural ahistórica puede ser aplicada a la evolución cultural. El autor considera que sí es posible, puesto que el propio Darwin contemplaba la posibilidad de la selección natural operar sobre variedades dirigidas y no exclusivamente genéticas; por ejemplo, puede utilizarse para explicar la variabilidad de las lenguas.

Por otro lado, se analiza cuál es el lugar de la teoría de la selección natural ahistórica en la biología evolutiva. Específicamente, detalla una comparación con la genética de poblaciones, mostrando que si bien se trata de teorías diferentes, ésta recurre a la capacidad explicativa de la teoría de la selección natural.

El libro de Ginnobili constituye un valioso aporte a la filosofía de la ciencia, y a la filosofía de la biología en particular, en al menos dos sentidos. Por un lado, propone una reconstrucción de la teoría de la selección natural de tal modo que podemos encontrar en ella todas las características de una teoría científica, lo cual ha sido puesto en cuestión: presenta una ley fundamental unificadora, con conceptos específicos asociados, y no difiere en líneas generales de otras teorías científicas en lo que refiere a su refutabilidad o tautologicidad. Por otro lado, resulta novedosa la aplicación de un enfoque de análisis que retoma las clásicas y abandonadas metas neopositivistas de reconstrucción racional de teorías y clarificación de conceptos, pretendiendo superarlas metodológicamente desde el marco del estructuralismo metateórico. Sin dudas, la reconstrucción que desarrolla esta investigación permite reflexionar sobre las potencialidades de tal metodología en lo que refiere al análisis metacientífico. 